\title{
Possible substellar companions in low-mass eclipsing binaries: GU Bootis and YY Geminorum
}

\author{
M. Wolf ${ }^{1}$, H. Kučáková ${ }^{1,2,3,4}$, P. Zasche ${ }^{1}$, J. Vraštil $^{1}$, K. Hoňková $^{4}$, K. Hornoch ${ }^{2}$, M. Lehký ${ }^{1,9}$, M. Mašek ${ }^{4}$, \\ L. Šmelcer ${ }^{4,5}$, M. Tylšar ${ }^{4,6}$, R. Novák ${ }^{7}$, L. Červinka ${ }^{4,8}$, and M. Bělík ${ }^{9}$ \\ 1 Astronomical Institute, Faculty of Mathematics and Physics, Charles University,V Holešovičkách 2, 18000 Praha 8 , \\ Czech Republic \\ e-mail: wolf@cesnet.cz \\ 2 Astronomical Institute, Academy of Sciences, Fričova 298, 25165 Ondřejov, Czech Republic \\ 3 Institute of Physics, Faculty of Philosophy and Science, Silesian University in Opava, Bezručovo nám. 13, 74601 Opava, Czech \\ Republic \\ 4 Variable Star and Exoplanet Section of the Czech Astronomical Society, Czech Republic \\ 5 Observatory Valašské Meziř́ííí, Vsetínská 78, 75701 Valašské Meziř́ičí, Czech Republic \\ 6 Observatory Prostějov, Kolářovy sady 3348, 79601 Prostějov, Czech Republic \\ 7 Faculty of Civil Engineering, University of Technology, Brno, Czech Republic \\ ${ }^{8}$ Observatory Mladá Boleslav, 29404 Dolní Bousov, Czech Republic \\ 9 Observatory Úpice, U Lipek 160, 54232 Úpice, Czech Republic
}

Received 25 June 2018 / Accepted 22 September 2018

\section{ABSTRACT}

\begin{abstract}
We present the next results of our long-term observational project to analyze the variations in the orbital periods of low-mass eclipsing binaries. About 70 new precise mid-eclipse times recorded with a CCD were obtained for two eclipsing binaries with short orbital periods: GU Boo $(P=0.49)$ and YY Gem $(0.81)$. Observed-minus-calculated diagrams of the stars were analyzed using all reliable timings, and new parameters of the light-time effect were obtained. We derived for the first time or improved the short orbital periods of possible third bodies of 11 and 54 years for these low-mass binaries, respectively. We calculated that the minimum masses of the third components are close to $50 M_{\text {Jup }}$, which corresponds to the mass of brown dwarfs. The multiplicity of these systems also plays an important role in the precise determination of their physical parameters.
\end{abstract}

Key words. binaries: eclipsing - stars: late-type - stars: individual: GU Bootis - stars: individual: YY Geminorum stars: fundamental parameters

\section{Introduction}

Low-mass stars and their multiple systems play an important role in stellar astrophysics. The origin of low-mass stars and brown dwarfs is still an unresolved question in star formation theory. Moreover, observations of low-mass stars show a discrepancy between estimated and modeled parameters, where the models give 5-10\% smaller radii than observations (Chabrier \& Baraffe 2000; Morales et al. 2010; Mann et al. 2015). The identification and characterization of low-mass multiples is also highly relevant to exoplanet studies.

Searching for substellar companions to short-period lowmass eclipsing binaries (LMB) sheds more light on the formation and evolution of planets and brown dwarfs. Because of the small size of the binary components, the eclipse times of this type of binary system can be determined with high precision, and very small amplitude variations in the orbital period can be detected by analyzing the observed-minus-calculated $(\mathrm{O}-\mathrm{C})$ diagram. This makes them very promising targets to search for circumbinary brown dwarfs or giant planets by analyzing the light-time effect (LITE). To date, several substellar companions to LMBs have been discovered using this efficient method (Lee et al. 2009; Hinse et al. 2012; Pribulla et al. 2012). Moreover, low-mass stars frequently exhibit phenomena associated with magnetic activity, such as flares and star spots.

We here report on a long-term mid-eclipse time campaign of two selected LMBs. These systems are all relatively well-known low-mass objects in the northern hemisphere. Their orbital periods are up to $20 \mathrm{~h}$, and spectroscopic observations have been published for both LMBs. This paper is a continuation of our previous period study of LMB presented in Wolf et al. (2016).

\section{Observations of mid-eclipses}

Long-term photometric observations for accumulating the mideclipse times are necessary when the O-C method is used to analyze the period variation. Short-period and detached LMBs with deep and symmetric eclipses enable us to obtain individual minimum times of eclipses with high accuracy. Moreover, this observing program is suitable for small amateur telescopes connected with modern detectors.

Since 2006 , we have accumulated nearly $10^{4}$ photometric observations during primary and secondary eclipses and derived about 80 precise times of minimum light for both systems. New CCD photometry was obtained mostly at the Ondřejov Observatory, Czech Republic, using the $0.65 \mathrm{~m}$ ( $f / 3.6)$ reflecting telescope with the CCD cameras Apogee AP7p or the Moravian 
Instruments G2-3200 and VRI photometric filters. The next precise CCD photometry was carried out at the Valašské Meziříčí Observatory, Czech Republic, using the $0.3 \mathrm{~m}$ Celestron Ultima telescope with the CCD camera SBIG ST-7 or G2-1600 and VRI filters, and with the Jan Šindel Telescope (JST) reflector $(0.40 \mathrm{~m}$ $f / 5)$ and G2-1600 CCD camera with a set of $V R$ bandpass filters operated at the observing house of the Astronomical Society in Hradec Králové. Additional measurements were obtained at the Prostějov and Mladá Boleslav observatories, where a $0.2 \mathrm{~m}$ Newtonian telescope and the CCD camera Atik 320E and MII G2-8300 without filter were used, respectively.

A standard calibration (dark frame, flat field) was applied to the observed CCD frames. Арнот, a synthetic aperture photometry and astrometry software, was routinely used for data obtained at Ondřejov observatory. C-MunIPACK ${ }^{1}$ was used to reduce our CCD time series obtained at Valašské Meziříčí, Hradec Králové, Mladá Boleslav and Prostějov. Differential photometry was performed using suitable comparison stars.

The computers at the telescope are synchronized using the time-server provided by tick . usno . navy . mil every two minutes. These corrections are usually on the order of $10^{-3} \mathrm{~s}$. The new times of primary and secondary minima and their errors were generally determined by fitting the light curve by Gaussians or polynomials of the third or fourth order; we used the leastsquares method. All new times are given in Tables A.1 and 3. The columns are self-explaining. If necessary, the times for the mid-eclipses are the averages of times obtained in two or three bandpasses.

All of the new timings we used in this analysis were first converted into barycentric Julian date dynamical time (BJD_TBD) using the time utilities of the Ohio State University ${ }^{2}$ (Eastman et al. 2010). Our new timings were combined with previously published times of minima, and where appropriate, the historic times were converted into BJD_TBD before analyses.

All new precise CCD times of minima were used with a weight of 10 in our computation. Some of our less precise measurements were weighted by a factor of 5, while the earlier visual times or times determined form sky surveys were given a weight of 1 or 0 because of the large scatter in these data. We found this traditional weighting scheme more reliable than using sometimes overestimated formal errors of individual mid-eclipse times obtained from different telescopes and light curves. We tested the stability of the results with respect to our somewhat arbitrarily chosen weighting scheme. The results show some dependence on the weighting, but this is mainly related to the less ideal distribution of available observations. For this reason, the results must be considered preliminary.

\section{Period variations}

An unseen circumbinary body can be detected by observing the timings of the mid-eclipse times of the eclipsing binary. The presence of an additional body causes a change in the relative distance of the eclipsing pair to the observer depending on the motion of the third body around the common barycenter of the system. As a result, the eclipses present delays or advances in the timings of minimum light. This well-known light-time effect (LITE) was introduced by Irwin $(1952,1959)$, who also gave a graphical fitting procedure for determining the elements of the light-time orbit. Later, the LITE was improved by Mayer (1990).

\footnotetext{
1 http://c-munipack. sourceforge.net/

2 http://astroutils.astronomy.ohio-state.edu/time/
}

See also Sterken (2005) for a short review on the application of $\mathrm{O}-\mathrm{C}$ diagrams in the analysis of period variations of different variable stars. If the orbital period of the third star is short (usually up to one year), then additional dynamical perturbations of the inner orbit can occur that also create changes in the mideclipse times (see Borkovits et al. 2011, 2016). The precise mideclipse time estimation enable us to find small apparent period changes and derive the physical parameters of the next orbiting bodies that are of a substellar size and mass.

We propose LITE in both systems studied by means of an $\mathrm{O}-\mathrm{C}$ diagram analysis. For an accurate calculation, the method originally described by Irwin (1952) and later extended by Mayer (1990) was applied. The least-squares method was used. Seven independent variables $\left(T_{0}, P_{\mathrm{s}}, P_{3}, e_{3}, A, \omega_{3}\right.$, and $\left.T_{3}\right)$ are determined in this procedure, where $P_{\mathrm{s}}$ is the orbital period of the binary, $P_{3}$ is the orbital period of the third body, $A$ is the semiamplitude of LITE, $e_{3}$ represents the eccentricity of the outer orbit, and $T_{3}$ is the periastron passage time of the third body. The zero epoch is given by $T_{0}$, and the corresponding position of the periastron is represented by $\omega_{3}$.

\subsection{GU Boo}

The detached eclipsing binary GU Boo (also NSVS 7820507, GSC 02566-00776, $V_{\max }=13^{\mathrm{m}} .11$, Sp. M0/1.5, Gaia parallax $6.146 \pm 0.015$ mas) is a relatively well-known northern low-mass binary and double-lined system with a short orbital period $(P=0.49 \mathrm{~d})$. It was discovered as a variable object by Diethelm (2001) in the Robotic Optical Transient Search Experiment database (ROTSE I, Akerlof et al. 2000). Later, López-Morales \& Ribas (2005) derived the first precise absolute dimensions and physical parameters. They identified this system as a low-mass binary composed of two similar stars of about $0.6 M_{\odot}$. The following linear light elements were derived by these authors:

Pri.Min. = HJD2452723. ${ }^{\mathrm{d}} 9811(3)+0 .{ }^{\mathrm{d}} 488728(2) \cdot \mathrm{E}$.

von Braun et al. (2008) presented a set of Spitzer 24 micron MIPS time series and confirmed the previously derived system parameters from optical studies. The effect of star spots on accurate radius determination was measured by Windmiller et al. (2010), who also confirmed the previous results of López-Morales \& Ribas (2005) at the level $2 \%$.

The additional measurements were obtained at Úpice observatory ( $0.2 \mathrm{~m}$ telescope without filter) and Prostějov observatory, where a $0.4 \mathrm{~m}$ telescope and the $V$ filter were used. The flare activity on this LMB was also captured during the monitoring of the secondary eclipse at Prostějov observatory on June 14, 2017 (see Fig 1). The brightness in $V$ band has suddenly increased by $0.37 \mathrm{mag}$ in BJD 2457919.4073.

The next timing of GU Boo was derived from the ASAS database (Pojmanski 2002) with lower precision. The Bootes-2 telescope ${ }^{3}$ in Spain (0.6 m RC telescope and CCD camera Andor iXon, Jelinek et al. 2016) was also used for the photometry of this object. All mid-eclipse times are listed in Table A.1, where epochs are calculated from the ephemeris given in Table 2. The data from Brát et al. (2009, 2011), Diethelm (2009, 2011, 2012), Zasche et al. (2011), and Hubscher (2017) were also included. A total of 125 times of minimum light were taken into our analysis, with 57 secondary eclipses among them. Several published times of amateur observers were omitted due to large scatter of

\footnotetext{
http://bootes.iaa.es/
} 
Table 1. New times of minimum light for GU Boo.

\begin{tabular}{lllccl}
\hline \hline $\begin{array}{l}\text { JD Hel.- } \\
2400000\end{array}$ & $\begin{array}{l}\text { BJD(TDB)- } \\
2400000\end{array}$ & $\begin{array}{l}\text { Error } \\
\text { (day) }\end{array}$ & Epoch & Weight & $\begin{array}{l}\text { Source } \\
\text { observatory }\end{array}$ \\
\hline 53818.49237 & 53818.49311 & 0.00008 & 2239.5 & 10 & Ondřejov \\
53846.59395 & 53846.59469 & 0.00007 & 2297.0 & 10 & Ondřejov \\
53860.52315 & 53860.52389 & 0.00012 & 2325.5 & 10 & Ondřejov \\
53866.38769 & 53866.38843 & 0.00013 & 2337.5 & 10 & Ondřejov \\
53898.39943 & 53898.40017 & 0.00010 & 2403.0 & 10 & Ondřejov \\
\hline
\end{tabular}

Notes. This table is available in its entirety in Appendix A.

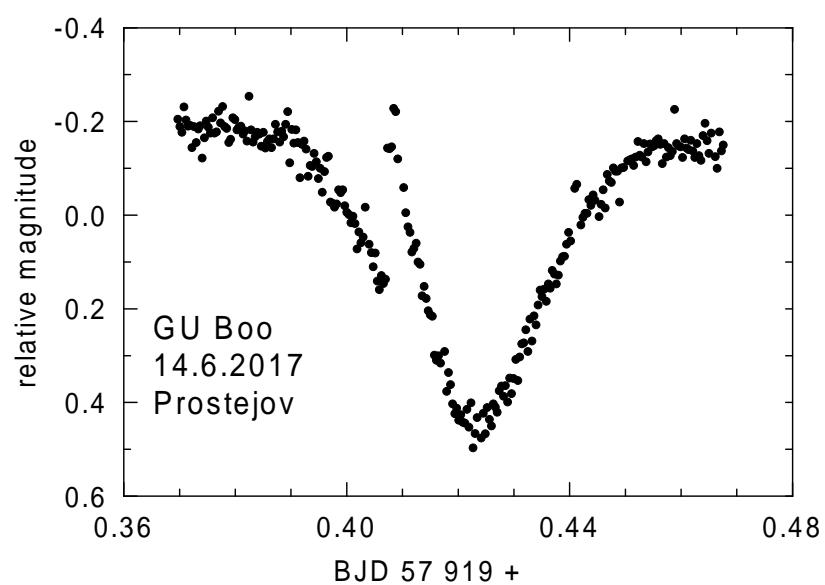

Fig. 1. $V$ light curve of the secondary eclipse of GU Boo obtained in Prostějov observatory on June 14, 2017. The flare is clearly visible on the descending branch of the light curve on BJD 2457919.4073.

these less precise data. The $\mathrm{O}-\mathrm{C}$ diagram is shown in Fig. 2, the computed LITE parameters and their internal errors of the least-squares fit are given in Table 2. It also lists the period ratio $P_{\mathrm{s}}^{2} / P_{3}$, which indicates possible dynamical interactions between the orbits that could be observed. $a_{12}$ is the semi-axis of the eclipsing-pair orbit around the common center of mass with the third body. The reduced chi-square value, $\chi_{\text {red }}^{2}$, is also calculated. The nonlinear prediction, corresponding to the fitted parameters, is plotted as a continuous blue curve.

\section{2. $Y Y$ Gem}

The detached eclipsing binary YY Geminorum (also Castor C, Gliese 278C, BD+32 1582, ADS 6175C, HD 60179C, $V_{\max }=$ $9^{\mathrm{m}} .27$, Sp. dM1e, Gaia parallax $66.23 \pm 0.05$ mas and the distance $15.1 \mathrm{pc}$ ) is a frequently studied low-mass and double-lined spectroscopic binary and a member of the nearby Castor multiple stellar system. It contains two nearly identical components with a well-known flare activity. It was discovered spectroscopically in 1916 by Adams \& Joy (1917); later, van Gent (1926) discovered eclipses and presented the first photographic light curve. YY Gem has been extensively studied in the past. The very precise absolute dimensions were obtained by Torres \& Ribas $\left(2002 ; M=0.5992 \pm 0.0047 M_{\odot}, R=0.6191 \pm 0.0057 R_{\odot}\right.$ and $T_{\text {eff }}=3820 \pm 100 \mathrm{~K}$ ) for two practically identical components. See also the investigation history of the Castor multiple system presented in that paper. Qian et al. (2002) later found that the orbital period shows a secular decrease with a rate $\sim 10^{-10}$ day $\mathrm{yr}^{-1}$. They conclude that the system is undergoing secular mass and angular momentum loss through a magnetic stellar wind. They also presented the improved light elements

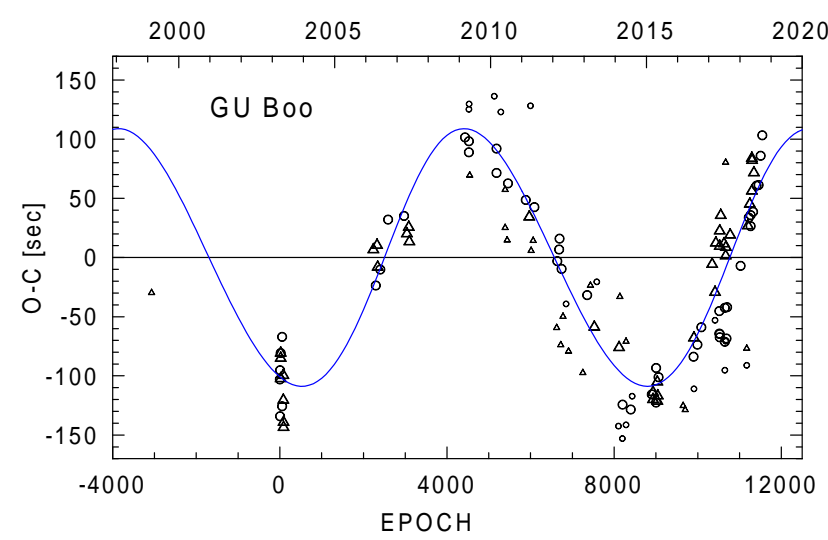

Fig. 2. Current $\mathrm{O}-\mathrm{C}$ diagram for the eclipse times of GU Boo. The sinusoidal curve represents the LITE with a period of 11.1 years. The individual primary and secondary minima are denoted by circles and triangles, respectively. Larger symbols correspond to the CCD measurements, which were given higher weights in the calculations.

\section{Pri. Min. $=$ HJD2424595 $.8172+0.81428254 \times \mathrm{E}$.}

Recently, a multiwavelength study of YY Gem was presented by Butler et al. (2015). They included broad-band optical, nearinfrared, ultraviolet, and radio data to determine the physical parameters and transient spots located near quadrature longitudes. New observations of eclipses were obtained at Mladá Boleslav and Prostějov observatories, where a $0.2 \mathrm{~m}$ Newtonian telescopes, Atik 320E, and the MII G2-8300 CCD camera were used, respectively. All mid-eclipse times of YY Gem given in Torres \& Ribas (2002, their Table 3) as well as in Agerer \& Hubscher (1999, 2002), Tas et al. (2004), Hubscher et al. (2009a,b, 2012), Hubscher (2011), Hubscher \& Lehman (2015), Hubscher (2016), Zasche et al. (2014), and new timings published on the O-C Gateway of the Variable Star and Exoplanet Section, Czech Astronomical Society $^{4}$, were included in our calculation with different weights. A total of 194 times of minimum light were used in our analysis, including 87 secondary eclipses. Many older visual mid-eclipse times were omitted due to the large scatter of these points. The computed LITE parameters are given in Table 2, the complete $\mathrm{O}-\mathrm{C}$ diagram is shown in Fig. 3.

\section{Discussion}

The detection of the LITE in LMBs enables us to test the stellar multiplicity in low-mass stars and also prove current models of stellar evolution. The derived parameters of the third-body orbit allow us to determine the mass function $f(M)$

\footnotetext{
4 http://var2.astro.cz/EN/
} 
Table 2. LITE parameters for selected LMBs (with errors of the last digit in parentheses).

\begin{tabular}{cccc}
\hline \hline Element & Unit & GU Boo & YY Gem \\
\hline$T_{0}$ & BJD & $2454723.98337(12)$ & $2424595.82174(18)$ \\
$P_{\mathrm{s}}$ & days & $0.48872947(5)$ & $0.81428219(1)$ \\
$P_{3}$ & days & $4040(60)$ & $19785(200)$ \\
$P_{3}$ & years & $11.1(2)$ & $54.2(5)$ \\
$e_{3}$ & - & $0.10(3)$ & $0.11(3)$ \\
$A$ & days & $0.00126(7)$ & $0.0034(2)$ \\
$\omega_{3}$ & deg & $14.5(32)$ & $37.6(25)$ \\
$T_{3}$ & BJD & $2454090(20)$ & $2454805(50)$ \\
$P_{\mathrm{s}}^{2} / P_{3}$ & days & $6 \times 10^{-5}$ & $3 \times 10^{-5}$ \\
$a_{12} \sin i$ & au & $0.22(1)$ & $0.58(3)$ \\
$\sum(\mathrm{O}-\mathrm{C})^{2}$ & day & $6.2 \times 10^{-5}$ & $6.4 \times 10^{-4}$ \\
$\chi_{\text {red }}^{2}$ & - & 2.45 & 27.5 \\
\hline
\end{tabular}

Notes. We used the SI definition of the speed of light $c=299792458 \mathrm{~m} \mathrm{~s}^{-1}$ in our calculation.

$f(M)=\frac{M_{3}^{3} \sin ^{3} i_{3}}{\left(M_{1}+M_{2}+M_{3}\right)^{2}}=\frac{1}{P_{3}^{2}}\left[\frac{173.15 A}{\sqrt{1-e_{3}^{2} \cos ^{2} \omega_{3}}}\right]^{3}$,

where $P_{3}$ is the period of the third body (in years) and $M_{i}$ are the component masses. The systemic radial velocity of the eclipsing pair has an amplitude (in $\mathrm{km} \mathrm{s}^{-1}$ ) of

$$
K=\frac{A}{P_{3}} \frac{5156}{\sqrt{\left(1-e_{3}^{2}\right)\left(1-e_{3}^{2} \cos ^{2} \omega_{3}\right)}} .
$$

Assuming a coplanar orbit $\left(i_{3} \sim 90^{\circ}\right)$, we can obtain a lower limit for the mass of the third component $M_{3 \text {,min }}$. These values for the third body of individual systems were calculated by iteration and are collected in Table 4. The amplitude of the dynamical contribution of the third body $A_{\mathrm{dyn}}$ is given approximately by (Borkovits et al. 2016)

$A_{\mathrm{dyn}}=\frac{1}{2 \pi} \frac{M_{3}}{M_{1}+M_{2}+M_{3}} \frac{P_{\mathrm{s}}^{2}}{P_{3}}\left(1-e_{3}^{2}\right)^{-3 / 2}$

and is also given in Table 4. The value of $A_{\text {dyn }}$ is on the order of seconds and is comparable with the precision of individual mid-eclipse time estimation.

Another possible mechanism for cyclical period variation is a magnetic activity cycle for systems with a late-type secondary star (Applegate 1992). However, the newly derived LITE periods for GU Boo $(\sim 11 \mathrm{yr})$ are too short for the magnetic cycle when compared with a mean value of about 40-50 yr in Algols and RS CVn binaries (Lanza \& Rodono 1999). This mechanism can contribute significantly to the observed period changes in YY Gem.

The reduced chi-square value, $\chi_{\text {red }}^{2}$, is satisfactory for GU Boo. This value is substantially higher than unity for YY Gem, caused very probably by the large scatter of older mideclipse times. For both LMBs we expect the brown dwarfs that are well below the mass limit of $0.075 M_{\odot}$ as the unseen third body orbiting the eclipsing pair. Moreover, the Castor stellar system could be at least septuple.

Additional timing variations with small amplitudes might be produced by the asymmetries of the eclipse light curves through stellar activity, such as star spots or small flares. The effect of star spots on the $\mathrm{O}-\mathrm{C}$ diagrams was studied by Kalimeris et al. (2002). They found that star spots modulate the O-C values and

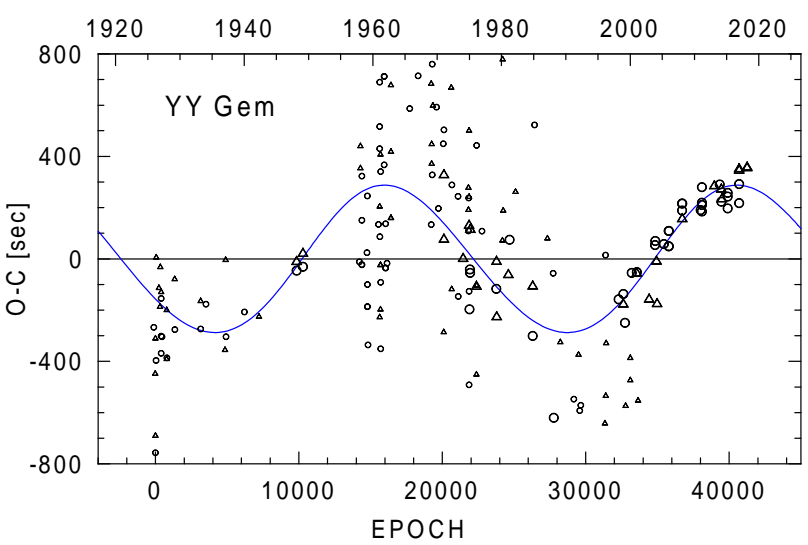

Fig. 3. O-C graph for YY Gem. See legend to Fig. 2. The sinusoidal curve represents the LITE with a period of about $55 \mathrm{yr}$ and an amplitude of $5 \mathrm{~min}$.

can introduce high-frequency and low-amplitude disturbances of less than $0.01 \mathrm{~d}$. These variations are caused by the change in the surface density and center of light over the visible hemisphere. Barros et al. (2013) showed that observed transit time variations in the hot-Jupiter WASP-10b system are also due to spot occultation features. Recently, Korda et al. (2017) tested the spot variability on the light curve of low-mass binaries and found a difference in mid-eclipse times of about $95 \mathrm{~s}$.

It is possible that circumbinary companions may be detected to transit these binary systems, especially if their orbital plane is closely aligned with the orbital plane of the binary system. Our predicted circumbinary companions have orbital periods measured in years and orbital distances in au, giving them a low probability of detecting a transit.

On the other hand, the probable brown dwarf could be confirmed spectroscopically using modern precise spectrographs connected to medium-size telescopes. The derived amplitudes of the systemic radial velocity of both LMB are on the order of hundreds of $\mathrm{m} / \mathrm{s}$ (Table 4). For YY Gem the previous measurements of radial velocity were obtained by Torres \& Ribas (2002) in the phase of the third-body orbital period near 0.8 . Their result $\gamma=0.54 \pm 0.26 \mathrm{~km} \mathrm{~s}^{-1}$ is close to the value $\gamma=1.97 \pm$ $0.24 \mathrm{~km} \mathrm{~s}^{-1}$ obtained by Ségransan et al. (2000) in practically the same phase. In 2019, we start at phase 0.2 of the long thirdbody orbit, which promises that we may be able to discover a detectable change in the systemic velocity of the binary. The previous radial-velocity curve of GU Boo was obtained in the phase 0.675 of the third-body orbital period (López-Morales \& Ribas 2005) and resulted in $\gamma=-24.57 \pm 0.36 \mathrm{~km} \mathrm{~s}^{-1}$. After 2019 , we can measure in phase up to 0.1 , thus it will be also possible to determine a change in the $\gamma$-velocity with a precision on the order of several hundreds of $\mathrm{m} / \mathrm{s}$.

\section{Conclusions}

Our analysis of $\mathrm{O}-\mathrm{C}$ diagrams has led to the identification of the next two probable triples in the known low-mass eclipsing binaries. The sinusoidal term in the orbital period is interpreted as the LITE being caused by a third body as the more likely scenario, most probably brown dwarfs of a similar mass about $50 M_{\text {Jup }}$. In both systems the whole third-body orbital period is now practically covered by the precise mid-eclipse times.

Our results contribute to this class of rare triple systems in our Galaxy (Tokovinin 2004; Raghavan et al. 2010). The sample of well-known LMB needs to be increased, and observations of additional systems would be very useful. 
Table 3. New times of minimum light for YY Gem.

\begin{tabular}{lllccl}
\hline \hline $\begin{array}{l}\text { JD Hel.- } \\
2400000\end{array}$ & $\begin{array}{l}\text { BJD(TDB)- } \\
2400000\end{array}$ & $\begin{array}{l}\text { Error } \\
\text { (day) }\end{array}$ & Epoch & Weight & $\begin{array}{l}\text { Source } \\
\text { observatory }\end{array}$ \\
\hline 53461.3113 & 53461.31204 & 0.0020 & 35449.0 & 1 & Brát et al. (2007) \\
$53744.6817 *$ & 53744.68216 & 0.0009 & 35797.0 & 10 & Brát et al. (2007) \\
56630.50029 & 56630.50105 & 0.00012 & 39341.0 & 10 & Zasche et al. (2014) \\
57735.48124 & 57735.48204 & 0.00019 & 40698.0 & 10 & Mladá Boleslav \\
57737.51762 & 57737.51848 & 0.00005 & 40700.5 & 10 & Mladá Boleslav \\
57739.55179 & 57739.55259 & 0.00013 & 40703.0 & 10 & Mladá Boleslav \\
58198.40145 & 58198.40228 & 0.00012 & 41266.5 & 10 & Prostějov \\
\hline
\end{tabular}

Table 4. Physical properties of the selected LMBs and parameters of their third bodies (with errors of the last digit in parentheses).

\begin{tabular}{cccc}
\hline \hline Parameter & Unit & GU Boo & YY Gem \\
\hline$M_{1}$ & $M_{\odot}$ & $0.6041(36)$ & $0.5992(47)$ \\
$M_{2}$ & $M_{\odot}$ & $0.5905(50)$ & $0.5992(47)$ \\
$R_{1}$ & $R_{\odot}$ & $0.6372(42)$ & $0.6191(57)$ \\
$R_{2}$ & $R_{\odot}$ & $0.5998(68)$ & $0.6191(57)$ \\
Source & & Windmiller et al. $(2010)$ & Torres \& Ribas $(2002)$ \\
\hline$f\left(m_{3}\right)$ & $M_{\odot}$ & $8.6(17) \times 10^{-5}$ & $6.4(9) \times 10^{-5}$ \\
$M_{3, \text { min }}$ & $M_{\odot}$ & $0.052(10)$ & $0.047(6)$ \\
$M_{3, \text { min }}$ & $M_{\text {Jupiter }}$ & $54(11)$ & $49(7)$ \\
$K$ & $\mathrm{~km} \mathrm{~s}^{-1}$ & 0.56 & 0.3 \\
$A_{\text {dyn }}$ & $\mathrm{s}$ & 8 & 4 \\
\hline
\end{tabular}

Acknowledgements. This research was supported by the Research Program MSM0021620860 Physical Study of objects and processes in the Solar System and in Astrophysics of the Ministry of Education of the Czech Republic and partially by the Czech Science Foundation, grant P209/10/0715, and in its final stage by the grant GA15-02112S. K.H. was supported by the project RVO: 67985815. The authors would also like to thank Lenka Kotková, Ondřejov observatory, Marek Chrastina and Dalibor Hanžl, Masaryk University Brno, for their important contribution to photometric observations. The following internetbased resources were used in research for this paper: the SIMBAD database and the VizieR service operated at CDS, Strasbourg, France; the NASA's Astrophysics Data System Bibliographic Services. This work has made use of data from the European Space Agency (ESA) mission Gaia (https://www. cosmos.esa.int/gaia), processed by the Gaia Data Processing and Analysis Consortium (DPAC, https://www. cosmos.esa.int/web/gaia/dpac/ consortium). Funding for the DPAC has been provided by national institutions, in particular the institutions participating in the Gaia Multilateral Agreement. This research is part of an ongoing collaboration between professional astronomers and the Czech Astronomical Society, Variable Star and Exoplanet Section. We gratefully acknowledge very useful suggestions by the referee.

\section{References}

Adams, W. S., \& Joy, A. H. 1917, ApJ, 46, 313 Agerer, F., \& Hubscher, J. 1999, IBVS No. 4711 Agerer, F., \& Hubscher, J. 2002, IBVS No. 5296

Akerlof, C., Amrose, S., Balsano, R., et al. 2000, AJ, 119, 1901 Applegate, J. H. 1992, ApJ, 385, 621

Baraffe, I., Chabrier, G., Allard, F., \& Hauschild, P. H. 1998, A\&A, 337, 403

Barros, S. C. C., Boué, G., Gibson, N. P., et al. 2013, MNRAS, 430, 3032

Borkovits, T., Csizmadia, Sz, Forgacs-Dajka, E., et al. 2011, A\&A, 528, A53

Borkovits, T., Hajdu, T., Sztakovics, J., et al. 2016, MNRAS, 455, 4136

Brát, L., Zejda, M. \& Svoboda, P. 2007, OEJV, 74

Brát, L., Trnka, J., Lehký, M., et al. 2009, OEJV, 107

Brát, L., Trnka, J., Šmelcer, L., et al. 2011, OEJV, 137

Butler, C. J., Erkan, N., Budding, E., et al. 2015, MNRAS, 446, 4205

Chabrier, G., \& Baraffe, I. 2000, ARA\&A, 38, 337

Diethelm, R. 2001, IBVS No. 5060

Diethelm, R. 2009, IBVS No. 5894

Diethelm, R. 2010, IBVS No. 5920

Diethelm, R. 2011, IBVS No. 5992

Diethelm, R. 2012, IBVS No. 6029
Diethelm, R. 2013, IBVS No. 6063

Eastman, J., Siverd, R., \& Gaudi, B. S. 2010, PASP, 122, 935

Hinse, T. C., Lee, J. W., Gozdziewski, K., et al. 2012, MNRAS, 420, 3609

Hoňková, K., Juryšek, J., Lehký, M., et al. 2013, OEJV, 160, 1

Hoňková, K., Juryšek, J., Lehký, M., et al. 2015, OEJV, 168

Hubscher, J. 2011, IBVS No. 5984

Hubscher, J. 2016, IBVS No. 6157

Hubscher, J. 2017, IBVS No. 6149

Hubscher, J., \& Lehman 2015, IBVS No. 6149

Hubscher, J., Lehmann, P. B., \& Walter, F. 2012, IBVS No. 6010

Hubscher, J., Steinbach, H. M., \& Walter, F. 2009a, IBVS No. 5874

Hubscher, J., Steinbach, H. M., \& Walter, F. 2009b, IBVS No. 5889

Irwin, J. B. 1952, ApJ, 116, 211

Irwin, J. B. 1959, AJ, 64, 149

Jelinek, M., Castro-Tirado, A. J., Cunniffe, R., et al. 2016, Adv. Astron., 1928465 Juryšek, J., Hoňková, K., Šmelcer, L., et al. 2017, OEJV, 179

Kalimeris, A., Rovithis-Livaniou, H., \& Rovithis, P. 2002, A\&A, 387, 969

Korda, D., Zasche, P., Wolf, M., et al. 2017, AJ, 154, 30

Lanza, A. F., \& Rodono, M. 1999, A\&A, 349, 887

Lee, J. W., Kim, S. L., Kim, C. H., et al. 2009, AJ, 137, 3181

López-Morales, M., \& Ribas, I. 2005, ApJ, 631, 1120

Mann, A. W., Feiden, G. A., Gaidos, E., et al. 2015, ApJ, 804, 64

Mayer, P. 1990, Bull. Astr. Inst. Czech., 41, 231

Morales, J. C., Gallardo, J., Ribas, I., et al. 2010, ApJ, 718, 502

Paschke, A. 2014, OEJV, 162

Pojmanski, G. 2002, AcA, 52, 397

Pribulla, T., Vaňko, M., Ammler-von Eiff, M., et al. 2012, Astron. Nachr., 333, 754

Qian, S., Liu, D., Tan, W., et al. 2002, AJ, 124, 1060

Raghavan, D., McAlister, H. A., Henry, T. J., et al. 2010, ApJS, 190, 1

Riaz, R., Vanaverbeke, S., \& Schleicher, D. R. G. 2018, MNRAS, 478, 5460

Ségransan, D., Delfosse, X., Forveille, T., et al. 2000, A\&A, 364, 665

Sterken, C. 2005, in The Light-Time Effect in Astrophysics, Proc of ASP Conf Series, 335

Tas, G., Sipahi, E., Dal, H. A., et al. 2004, IBVS No. 5548

Tokovinin, A. 2004, Rev. Mex. Astron. Astrofis. Conf. Ser., 21, 7

Torres, G., \& Ribas, I. 2002, ApJ, 567, 1140

von Braun, K., van Belle, G. T., Ciardi, D. R. et al. 2008, ApJ, 677, 545

van Gent, H. 1926, BAN, 3, 121

Windmiller, G., Orosz, J. A., \& Etzel, P. B. 2010, ApJ, 712, 1003

Wolf, M., Zasche, P., Kučáková, H., et al. 2016, A\&A, 587, A82

Zasche, P., Uhlař, R., Kučáková, H., et al. 2011, IBVS No. 6007

Zasche, P., Uhlař, R., Kučáková, H., et al. 2014, IBVS No. 6114 


\section{Appendix A: Tables of mid-eclipse times}

Table A.1. Minima timings of GU Boo.

\begin{tabular}{|c|c|c|c|c|c|}
\hline $\begin{array}{l}\text { BJD(TDB)- } \\
2400000\end{array}$ & $\begin{array}{l}\text { JD Hel.- } \\
2400000\end{array}$ & $\begin{array}{l}\text { Error } \\
\text { (day) }\end{array}$ & Epoch & Weight & $\begin{array}{l}\text { Source } \\
\text { observatory }\end{array}$ \\
\hline 53818.49311 & 53818.49237 & 0.00008 & 2239.5 & 10 & Ondřejov \\
\hline 53846.59469 & 53846.59395 & 0.00007 & 2297.0 & 10 & Ondřejov \\
\hline 53860.52389 & 53860.52315 & 0.00012 & 2325.5 & 10 & Ondřejov \\
\hline 53866.38843 & 53866.38769 & 0.00013 & 2337.5 & 10 & Ondřejov \\
\hline 53898.40017 & 53898.39943 & 0.00010 & 2403.0 & 10 & Ondřejov \\
\hline 53988.32688 & 53988.32614 & 0.00009 & 2587.0 & 10 & Ondřejov \\
\hline 54175.51030 & 54175.50956 & 0.00007 & 2970.0 & 10 & Ondřejov \\
\hline 54210.45430 & 54210.45356 & 0.00009 & 3041.5 & 10 & Ondřejov \\
\hline 54231.46973 & 54231.46899 & 0.00011 & 3084.5 & 10 & Ondřejov \\
\hline 54237.33434 & 54237.33360 & 0.00018 & 3096.5 & 10 & Ondřejov \\
\hline 54888.56736 & 54888.5666 & 0.0001 & 4429.0 & 5 & AAVSO \\
\hline 54935.48536 & 54935.4846 & 0.0001 & 4525.0 & 5 & Brát et al. (2011) \\
\hline 54936.46313 & 54936.4624 & 0.0020 & 4527.0 & 1 & Brát et al. (2011) \\
\hline 54937.44064 & 54937.4399 & 0.0020 & 4529.0 & 1 & Brát et al. (2011) \\
\hline 54943.54907 & 54943.5483 & 0.0001 & 4541.5 & 1 & Hradec Králové \\
\hline 54965.78527 & 54965.7845 & 0.0005 & 4587.0 & 1 & Diethelm (2009) \\
\hline 55231.65585 & 55231.6551 & 0.0001 & 5131.0 & 1 & Brát et al. (2011) \\
\hline 55258.53534 & $55258.53457 *$ & 0.00012 & 5186.0 & 5 & Brno \\
\hline 55309.36368 & 55309.3629 & 0.0005 & 5290.0 & 1 & Brát et al. (2011) \\
\hline 55357.50258 & $55357.5018^{*}$ & 0.0002 & 5388.5 & 1 & Brno \\
\hline 55382.42750 & 55382.4267 & 0.0002 & 5439.5 & 1 & Brát et al. (2011) \\
\hline 55392.44700 & 55392.44622 & 0.00008 & 5460.0 & 10 & Ondřejov \\
\hline 55599.66813 & $55599.6673 *$ & 0.0002 & 5884.0 & 5 & Hoňková et al. (2013) \\
\hline 55640.47689 & 55640.47611 & 0.00012 & 5967.5 & 10 & Ondřejov \\
\hline 55654.89548 & 55654.8947 & 0.0009 & 5997.0 & 1 & Diethelm (2011) \\
\hline 55662.46940 & 55662.4686 & 0.0009 & 6012.5 & 1 & Hoňková et al. (2013) \\
\hline 55687.39468 & $55687.3939 *$ & 0.0002 & 6063.5 & 1 & Hoňková et al. (2013) \\
\hline 55700.34633 & 55700.34555 & 0.0001 & 6090.0 & 10 & Zasche et al. (2011) \\
\hline 55798.33584 & 55789.33506 & 0.00008 & 6290.5 & 10 & Ondřejov \\
\hline 55963.52593 & $55963.52515^{*}$ & 0.0003 & 6628.5 & 1 & Hoňková et al. (2013) \\
\hline 55968.65828 & $55968.6574 *$ & 0.0002 & 6639.0 & 10 & Hoňková et al. (2013) \\
\hline 55991.62868 & 55991.62790 & 0.00008 & 6686.0 & 10 & Ondřejov \\
\hline 55996.51611 & 55996.5153 & 0.0002 & 6696.0 & 5 & Hoňková et al. (2013) \\
\hline 56009.46638 & $56009.4656^{*}$ & 0.0004 & 6722.5 & 1 & Hoňková et al. (2013) \\
\hline 56019.48607 & 56019.48529 & 0.00011 & 6743.0 & 10 & Ondřejov \\
\hline 56036.34678 & 56036.3460 & 0.0002 & 6777.5 & 1 & Hoňková et al. (2013) \\
\hline 56071.77978 & 56071.779 & 0.005 & 6850.0 & 1 & Paschke (2014) \\
\hline 56100.37000 & 56100.36922 & 0.00012 & 6908.5 & 1 & Ondřejov \\
\hline 56268.49272 & 56268.492 & 0.001 & 7252.5 & 1 & ASAS \\
\hline 56318.58825 & 56318.58746 & 0.00011 & 7355.0 & 10 & Ondřejov \\
\hline 56356.46489 & $56356.4641 *$ & 0.0003 & 7432.5 & 1 & Hoňková et al. (2013) \\
\hline 56400.45014 & 56400.44935 & 0.00012 & 7522.5 & 10 & Ondřejov \\
\hline 56431.48488 & $56431.4841 *$ & 0.0001 & 7586.0 & 1 & Hoňková et al. (2013) \\
\hline 56683.66788 & $56683.6671 *$ & 0.0003 & 8102.0 & 1 & Hoňková et al. (2015) \\
\hline 56692.71016 & 56692.70938 & 0.00009 & 8120.5 & 10 & Ondřejov \\
\hline 56701.50778 & $56701.5070^{*}$ & 0.0002 & 8138.5 & 1 & Hoňková et al. (2015) \\
\hline 56711.52510 & 56711.5243 & 0.0003 & 8159.0 & 1 & Ondřejov \\
\hline 56712.50228 & $56712.5015^{*}$ & 0.0002 & 8161.0 & 5 & Hoňková et al. (2015) \\
\hline 56730.58579 & 56730.5850 & 0.0001 & 8198.0 & 1 & Hoňková et al. (2015) \\
\hline 56731.56358 & 56731.5628 & 0.0001 & 8200.0 & 5 & Ondřejov \\
\hline
\end{tabular}

Notes. ${ }^{(*)}$ Mean value of $V R, R I$, or $V R I$ measurements. 
Table A.1. continued.

\begin{tabular}{|c|c|c|c|c|c|}
\hline $\begin{array}{l}\text { BJD(TDB)- } \\
2400000\end{array}$ & $\begin{array}{l}\text { JD Hel.- } \\
2400000\end{array}$ & $\begin{array}{l}\text { Error } \\
\text { (day) }\end{array}$ & Epoch & Weight & $\begin{array}{l}\text { Source } \\
\text { observatory }\end{array}$ \\
\hline 56773.59411 & 56773.593 & 0.001 & 8286.0 & 1 & ASAS \\
\hline 56773.83930 & 56773.839 & 0.001 & 8286.5 & 1 & ASAS \\
\hline 56827.35451 & 56827.35373 & 0.00011 & 8396.0 & 5 & Ondřejov \\
\hline 56845.43763 & 56845.4369 & 0.0001 & 8433.0 & 1 & Hoňková et al. (2015) \\
\hline 57074.65176 & 57074.6510 & 0.0005 & 8902.0 & 5 & ASAS \\
\hline 57089.55798 & 57089.55721 & 0.00007 & 8932.5 & 10 & Ondřejov \\
\hline 57089.55805 & 57089.55728 & 0.00012 & 8932.5 & 10 & Bootes-2 \\
\hline 57125.47972 & $57125.4790 *$ & 0.0002 & 9006.0 & 5 & Juryšek et al. (2017) \\
\hline 57139.40847 & $57139.4077 *$ & 0.0002 & 9034.5 & 5 & Juryšek et al. (2017) \\
\hline 57143.31826 & 57143.31749 & 0.00014 & 9042.5 & 10 & Ondřejov \\
\hline 57153.33738 & 57153.33661 & 0.00009 & 9063.0 & 10 & Ondřejov \\
\hline 57208.56288 & 57208.562 & 0.001 & 9176.0 & 1 & ASAS \\
\hline 57441.44317 & 57441.442 & 0.001 & 9652.5 & 1 & ASAS \\
\hline 57464.41337 & 57464.4126 & 0.0001 & 9699.5 & 1 & Hubscher (2017) \\
\hline 57464.65667 & 57464.6559 & 0.0001 & 9700.0 & 1 & Hubscher (2017) \\
\hline 57562.40414 & 57562.40337 & 0.00008 & 9900.0 & 10 & Ondřejov \\
\hline 57567.29112 & 57567.290 & 0.001 & 9910.0 & 1 & ASAS \\
\hline 57567.53600 & 57567.5352 & 0.0005 & 9910.5 & 5 & ASAS \\
\hline 57607.36737 & 57607.3666 & 0.0001 & 9992.0 & 10 & Ondřejov \\
\hline 57654.28557 & 57654.28480 & 0.00009 & 10088.0 & 10 & Ondřejov \\
\hline 57780.62277 & 57780.62199 & 0.00007 & 10346.5 & 10 & Ondřejov \\
\hline 57813.61148 & 57813.611 & 0.001 & 10414.0 & 1 & ASAS \\
\hline 57813.85608 & 57813.8553 & 0.0005 & 10414.5 & 5 & ASAS \\
\hline 57824.60863 & 57824.60785 & 0.00013 & 10436.5 & 10 & Ondřejov \\
\hline 57864.43918 & 57864.43840 & 0.00015 & 10518.0 & 5 & Úpice \\
\hline 57864.43940 & 57864.43862 & 0.00015 & 10518.0 & 5 & Prostějov \\
\hline 57868.34900 & $57868.34822 *$ & 0.00012 & 10526.0 & 5 & Valašské Meziříčí \\
\hline 57868.59433 & $57868.59355^{*}$ & 0.00014 & 10526.5 & 5 & Hradec Králové \\
\hline 57880.32406 & 57880.3233 & 0.0003 & 10550.5 & 5 & Ondřejov \\
\hline 57918.44468 & 57918.4439 & 0.0002 & 10628.5 & 5 & Prostějov \\
\hline 57929.43984 & 57929.4391 & 0.0005 & 10651.0 & 1 & Valašské Meziříčí \\
\hline 57929.44028 & $57929.4395 *$ & 0.0001 & 10651.0 & 5 & Hradec Králové \\
\hline 57938.48247 & 57938.4817 & 0.0001 & 10669.5 & 10 & Prostějov \\
\hline 57938.72598 & 57938.725 & 0.001 & 10670.0 & 1 & ASAS \\
\hline 57938.97208 & 57938.971 & 0.001 & 10670.5 & 1 & ASAS \\
\hline 57941.41493 & 57941.4142 & 0.0002 & 10675.5 & 5 & Ondřejov \\
\hline 57948.50060 & 57948.4998 & 0.0001 & 10690.0 & 5 & Valašské Meziříčí \\
\hline 57954.36566 & 57954.3649 & 0.0001 & 10702.0 & 5 & Valašské Meziříčí \\
\hline 57989.31054 & 57989.30976 & 0.00018 & 10773.5 & 5 & Ondřejov \\
\hline 58113.69187 & 58113.69109 & 0.00012 & 11028.0 & 10 & Ondřejov \\
\hline 58184.06798 & 58184.067 & 0.001 & 11172.0 & 1 & ASAS \\
\hline 58184.31248 & 58184.312 & 0.001 & 11172.5 & 1 & ASAS \\
\hline 58198.48684 & 58198.4861 & 0.0001 & 11201.5 & 5 & Prostějov \\
\hline 58207.52840 & 58207.5276 & 0.0002 & 11220.0 & 5 & Ondřejov \\
\hline 58219.50242 & 58219.5016 & 0.0002 & 11244.5 & 5 & Ondřejov \\
\hline 58229.52114 & $58229.52036^{*}$ & 0.00014 & 11265.0 & 5 & Hradec Králové \\
\hline 58229.52125 & 58229.52047 & 0.00013 & 11265.0 & 5 & Prostějov \\
\hline 58245.40538 & $58245.4046 *$ & 0.0001 & 11297.5 & 5 & Hradec Králové \\
\hline 58246.38297 & 58246.3822 & 0.0001 & 11299.5 & 5 & Valašské Meziříčí \\
\hline 58258.35632 & 58258.3555 & 0.0002 & 11324.0 & 5 & Prostějov \\
\hline 58269.35313 & 58269.35235 & 0.00018 & 11346.5 & 5 & Ondřejov \\
\hline 58300.38731 & 58300.3865 & 0.0002 & 11410.0 & 10 & Ondřejov \\
\hline 58323.35760 & 58323.3568 & 0.0002 & 11457.0 & 5 & Valašské Meziříčí \\
\hline 58347.30564 & 58347.30485 & 0.00017 & 11506.0 & 10 & Ondřejov \\
\hline 58366.36629 & 58366.3655 & 0.0002 & 11545.0 & 10 & Ondřejov \\
\hline
\end{tabular}

